\title{
Temporal Patterns of Shrub Vegetation and Variation with Precipitation in Gurbantunggut Desert, Central Asia
}

\author{
Yuguang Yang, ${ }^{1,2}$ Chengyi Zhao, ${ }^{1}$ Ming Han, ${ }^{1,2}$ Yike Li, ${ }^{1,2}$ and Ruihong Yang ${ }^{1,3}$ \\ ${ }^{1}$ State Key Laboratory of Desert and Oasis Ecology, Xinjiang Institute of Ecology and Geography, CAS, Urumqi 830011, China \\ ${ }^{2}$ University of Chinese Academy of Sciences, Beijing 100049, China \\ ${ }^{3}$ Xinjiang Education Institute, Urumqi 840043, China
}

Correspondence should be addressed to Chengyi Zhao; zcy@ms.xjb.ac.cn

Received 11 December 2014; Accepted 26 January 2015

Academic Editor: Marcos Heil Costa

Copyright (C) 2015 Yuguang Yang et al. This is an open access article distributed under the Creative Commons Attribution License, which permits unrestricted use, distribution, and reproduction in any medium, provided the original work is properly cited.

\begin{abstract}
The relationship between shrub vegetation and precipitation is one important component of desert vegetation responses to climate change, but it has not been understood completely because of its complexity and nonlinearity. In this study, we used MODIS NDVI data and precipitation data from 2004 to 2012 to evaluate the relationship between the shrub vegetation and precipitation within Gurbantunggut Desert, Central Asia. Correlation analysis was employed to explore the relationship between NDVI and precipitation within growing season, within cross growing season, and on interannual scale. The results showed that NDVI could be classified into three temporal changing patterns within growing season, and NDVI was significantly correlated with the precipitation integrated by time durations and time lags within growing season; NDVI was significantly correlated with precipitation in the early growing season, but this relationship was not so obvious in the middle or late growing season; and the NDVI variational patterns depended on mean annual precipitation and the distribution of precipitation throughout the year. Precipitation had significant influence on shrub vegetation within Gurbantunggut Desert. Our findings provide basic knowledge for the relationship between precipitation and shrub vegetation, and it is helpful to understand how the desert vegetation responds to climate change in the future.
\end{abstract}

\section{Introduction}

Desert is typically one kind of water-limited ecosystems, which has low precipitation and high potential evapotranspiration [1-3]. How desert vegetation responds to climate change, such as variation in precipitation, is a wide concern for the ecologists and the meteorologists, and many researches have addressed this issue [4-7].

Shrub vegetation links the soil and atmosphere, displays seasonal and annual changes obviously, and acts as a sensitive indicator of climate changes in shrubland, which is vastly distributed in the desert $[8,9]$. Precipitation is the primary supplier for soil water in the desert, where soil water is a strong limiting factor for vegetation growth within a year [10-15]; thus studying how the shrub vegetation responds to precipitation variation is one important component of desert vegetation responses to climate change.
On global scale, mean annual precipitation is one of the best predictors of vegetation production $[16,17]$. But the relationship between precipitation and vegetation is remaining uncertain because of complex ecohydrology process on different spatial-temporal scales. Several studies demonstrated that there is no or only a weak relationship between interannual precipitation and vegetation production in some sites $[16,18,19]$; several studies demonstrated that there is a strong relationship between precipitation and vegetation production in other sites [20-22]; and several studies showed that vegetation could strongly respond to precipitation in different time lags and durations [16, 23-27], just like the pulsereserve paradigm, which indicate that vegetation growth following a precipitation event is dependent on the intervals between precipitation events and the necessary duration when the vegetation can obtain sufficient water to initiate biomass production [28]. The mechanism, extent, and time of 

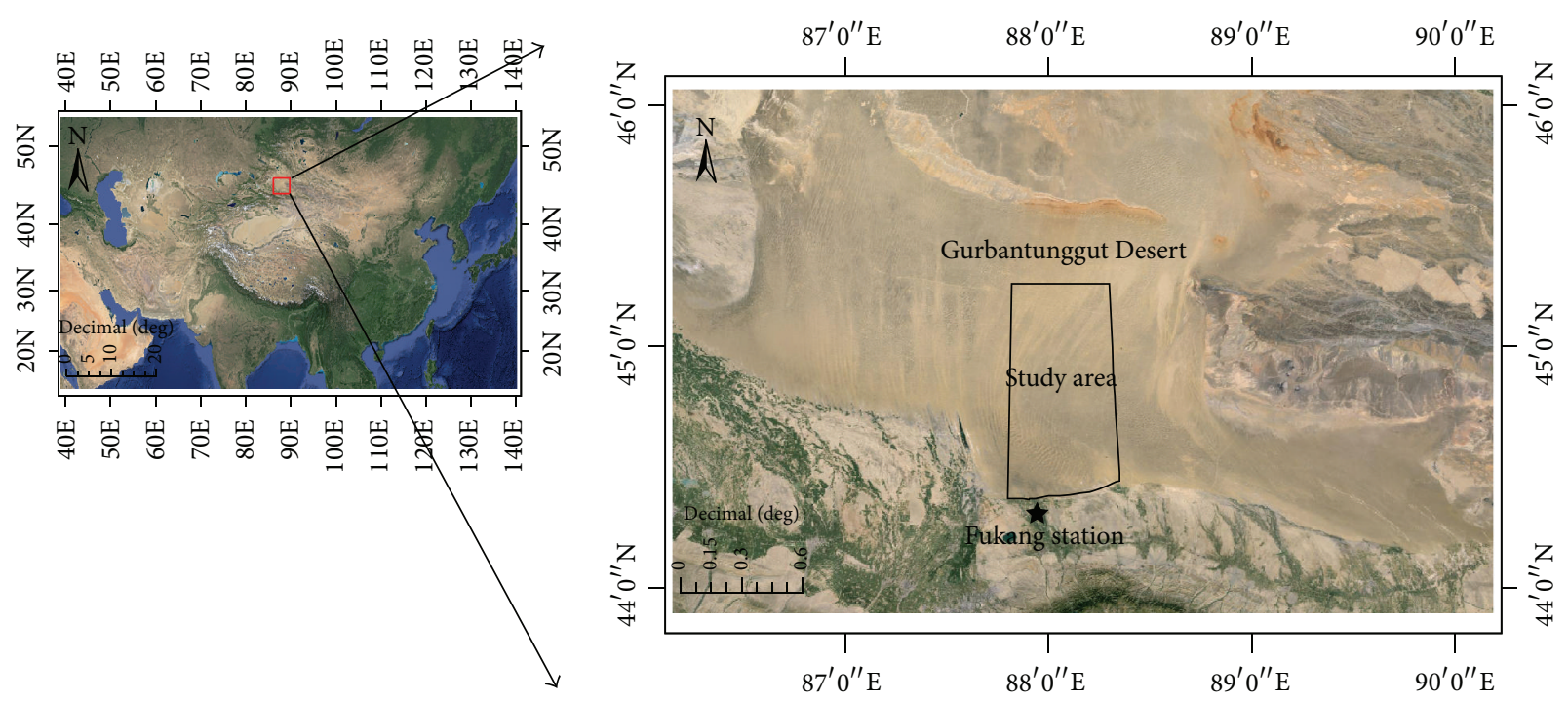

FIGURE 1: Description of the location of the automatic weather station and study area from Google Earth.

the influence of precipitation on vegetation are far from being completely understood.

NDVI, a kind of vegetation index which is very significant to reflect the information of vegetation, is widely used to be an indicator of growth status, spatial density distribution and phenology of plant, and productivity and biomass of ecosystem since the 1980s, and it is an effective method to study the vegetation in the ecosystem-level $[9,26]$. The values of NDVI range from -1.0 to 1.0 , and increasing positive NDVI values indicate increasing amounts of green vegetation; NDVI value is near zero or negative, which indicates nonvegetated features, such as barren surfaces (rock or soil), water, snow, ice, and clouds $[9,29]$. MODIS NDVI products, like MOD13Q1, were widely used because of their high temporal resolution and moderate spatial resolution [23, 30-34].

In this study, we used the MOD13Q1 product data and precipitation data to evaluate the relationship between shrub vegetation and precipitation within Gurbantunggut Desert within growing season, within cross growing season, and on interannual scale. The main objects of this research are (1) to explore the temporal patterns of shrub vegetation variability characteristics during the growing season; (2) to examine the relationship between shrub vegetation and precipitation on different time scales; and (3) to explore the patterns that the shrub vegetation responds to precipitation variability.

\section{Materials and Methods}

2.1. Study Area. The study area is located in the southern edge of Gurbantunggut Desert. The region is about $3,315 \mathrm{~km}^{2}$ and located between $44^{\circ} 22^{\prime}-45^{\circ} 06^{\prime} \mathrm{N}$ and $87^{\circ} 47^{\prime}-88^{\circ} 21^{\prime} \mathrm{E}$ (Figure 1). The altitude in the region varies from 424 to $729 \mathrm{~m}$ above mean sea level. The vegetation is dominated by Haloxylon ammodendron, Haloxylon persicum, and other common species, including Calligonum leucocladum, Alhagi sparsifolia Shap., and Ceratocarpus arenarius L. The vegetation growth mainly occurs from late March to early November. The vegetation is discontinuous with a total coverage of about $30 \%$, of which herbaceous plants account for less than $5 \%$. There are also some ephemeral species in spring. Soil is classified as sand loam [35-37].

The study area has an extremely arid climate, with a mean annual precipitation of $135 \mathrm{~mm}$ (70\% occurring in spring and summer) but with a potential annual evaporation of $2,000 \mathrm{~mm}$, and an average annual snow cover period is about 103 days in this area, starting from late November and ending in mid-March of the following year. The study site has a mean annual temperature of $4-6^{\circ} \mathrm{C}$ but with a hot summer (mean monthly maximum $32.6^{\circ} \mathrm{C}$, in July) and a cold winter (mean monthly minimum $-21.8^{\circ} \mathrm{C}$, in January) [35].

2.2. Data Collection and Processing. In the study, we used nine-year NDVI datasets in growing season (from DOY 81 to 305$)$ to evaluate the vegetation variation patterns in the study area. MODIS Terra vegetation indices 16 -day composite collection 5 level 1 at the tile of h24v4 at $250 \mathrm{~m}$ spatial resolution (MOD13Q1) in HDF format were acquired between 2004 and 2012 in the growing season, from the following website: http://ladsweb.nascom.nasa.gov/data/search.html, which is maintained by the NASA Land Processes Distributed Active Archive Center at the USGS [24]. The data format was transformed into GEOTiff format using the MRT software and the images were clipped using the study area border executed in ARCGIS 9.3 Software [24].

MOD13Q1 included NDVI band which provided information about growing conditions on the ground, and it was widely used as a representative for biomass production [24]. The means of all pixels (resolution $250 \mathrm{~m}$ per pixel) in the study area for all the 16-day products during the growing season were calculated as mean NDVI values of 16day periods, and the means of mean NDVI values of all 16-day periods during the growing seasons were calculated as yearly NDVI value. 
Precipitation data were captured by the Campbell automatic weather station (Campbell Scientific, Logan, UT, USA) located at Fukang Station of Desert Ecology, Chinese Academy of Sciences $\left(87^{\circ} 56^{\prime} \mathrm{E}, 44^{\circ} 17^{\prime} \mathrm{N}\right)$, approximately $10 \mathrm{~km}$ away from the study area, and they were measured at a frequency of $10 \mathrm{~Hz}$ and recorded every five minutes and then stored as 30 min mean data. The 30 min precipitation data were aggregated to daily data every day, and the daily data were aggregated to 16-day data to match the 16-day NDVI data, and the sum value of all daily precipitation data within a year was calculated as yearly data for every year; then the sum value for each of the 16-day data and its succeeding data of the year were calculated as accumulate precipitation of each 16day period.

2.3. Statistical Analysis. Pearson correlation analysis was used to examine the degree of correlation between precipitation and NDVI within growing season (within-season), cross growing seasons (cross-season), and cross years (interannual), just as Richard and Poccard (1998) and Wang et al. (2003) did in their studies [27, 38]. Within-season analyses examined the relationship between NDVI and precipitation in different 16-day periods of the same growing season for every year. Cross-season analyses examined the relationship between NDVI and precipitation in the same 16-day period through different growing seasons. Interannual analyses examined the relationship between NDVI and precipitation on yearly scale.

In order to analyze the relationship between NDVI and precipitation within growing season, the correlation coefficients between current NDVI and different combinations of duration and lag precipitation were calculated every year. We designed five different durations (1-5 16-day time durations) and six different time lags (0-5 16-day time lags) for precipitation. This resulted in a total of 30 different combinations as shown in Table 1 . Thus it was able to assess which combination (duration and lag) of precipitation mostly influenced current NDVI.

For analyzing the relationship between NDVI and precipitation on cross-season scale, the correlation coefficients between current NDVI and different combinations of duration and lag precipitation of the same 16-day period through different growing season were calculated. The result provided the evidence for distinguishing in which period during the growing season NDVI was mostly influenced by precipitation. The same analyses for NDVI and precipitation integrated over the same set of 30 precipitation combinations as within-season ( 5 durations $\times 6$ lags) were performed, which was helpful to assess which combination of duration and lag chiefly influenced current NDVI.

In order to analyze the interannual relationship between precipitation and NDVI, the correlation coefficient between the total precipitation and mean annual NDVI was calculated. Based on those analyses, how significantly the total annual precipitation correlated with the mean annual NDVI could be evaluated. And the correlation coefficients between accumulative precipitation in each 16-day period and annual mean NDVI were calculated to evaluate in which period
TABLE 1: The design of temporal patterns ( 5 time durations $\times 6$ time lags) of precipitation for analyzing the relationship between current NDVI and different combinations of duration and lag precipitation. The numbers in the cells indicated the time interval for which precipitation was accumulated ( 0 indicated the current 16-day period, 1 indicated the first previous period, 2 indicated the second previous period, $0-1$ indicated precipitation was accumulated from current period to the first previous period, $0-2$ indicated precipitation was accumulated from current period to the second previous period, etc.).

\begin{tabular}{lccccc}
\hline Lag & \multicolumn{5}{c}{ Duration } \\
& 1 & 2 & 3 & 4 & 5 \\
\hline 0 & 0 & $0-1$ & $0-2$ & $0-3$ & $0-4$ \\
1 & 1 & $1-2$ & $1-3$ & $1-4$ & $1-5$ \\
2 & 2 & $2-3$ & $2-4$ & $2-5$ & $2-6$ \\
3 & 3 & $3-4$ & $3-5$ & $3-6$ & $3-7$ \\
4 & 4 & $4-5$ & $4-6$ & $4-7$ & $4-8$ \\
5 & 5 & $5-6$ & $5-7$ & $5-8$ & $5-9$ \\
\hline
\end{tabular}

the accumulative precipitation mainly influenced the annual mean NDVI.

\section{Results}

3.1. General Trends of NDVI and Precipitation during the Growing Season. The 16-day NDVI values of MOD13Q1 product for the natural shrubland during the growing season within Gurbantunggut Desert ranged from 0.0628 to 0.2618 , which were lower than that of other land-cover categories, like forest and cropland, and the NDVI values were polytropic within growing season between years. NDVI curves for the study area in the nine years could be divided into three categories according to the shapes of the curves in each growing season. The first category could be described as bimodal pattern (for the years of 2004, 2007, and 2011), the second category could be described as unimodal pattern (for the years of 2006, 2008, and 2009), and the last category could be described as no-peak pattern (for the years of 2005, 2010, and 2012). The NDVI value was peaked in May and August of the year that featured bimodal pattern and in late April and early June of the year that featured unimodal pattern, while it would be comparatively lower in the growing season of the year that featured no-peak pattern (Figure 2). Small precipitation (less than $5 \mathrm{~mm}$ ) was main and extreme precipitation (over $30 \mathrm{~mm}$ ) was rare in this area. And the precipitation happened unevenly in a year, mainly from April to August but seldom from September to March.

3.2. Within-Season Relationship between NDVI and Precipitation. There was a considerable year-to-year variation about the relationship between NDVI and precipitation. The correlation coefficients between precipitation and NDVI were high in the specific combination of time duration and lag. However, in the years that featured no-peak pattern, the correlation coefficients between precipitation and NDVI were lower than $P_{\alpha=0.05}=0.51$ in the year of 2005 and were negative in the year of 2012. In terms of duration, NDVI 

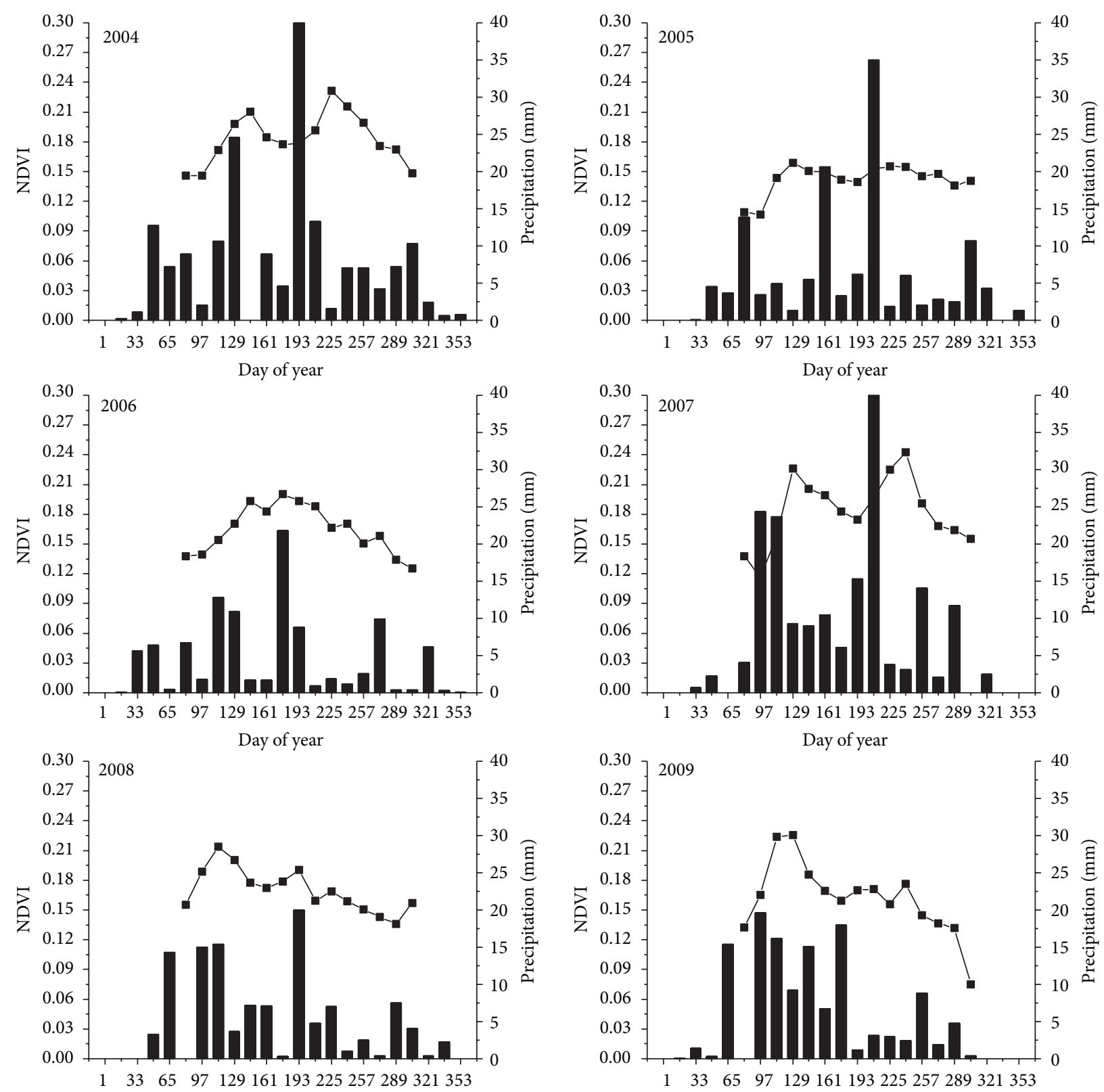

Day of year
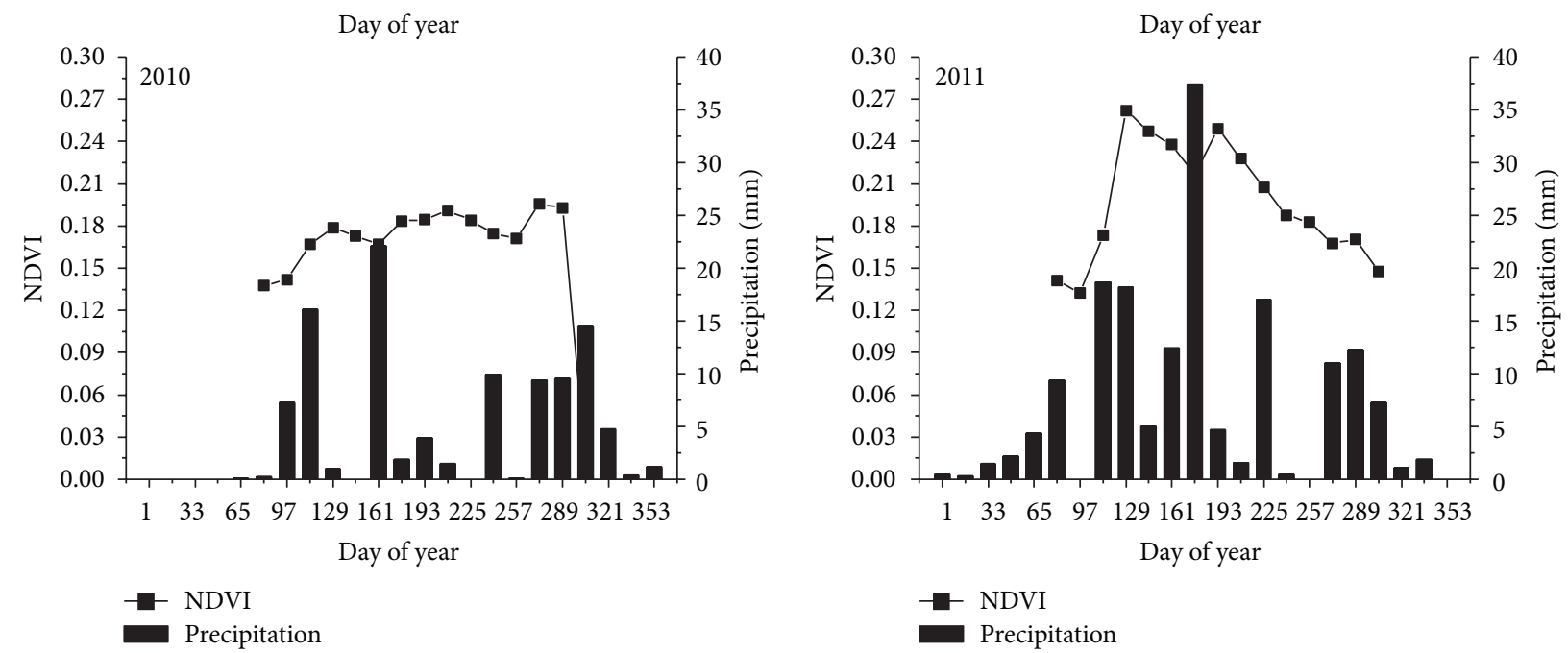

Figure 2: Continued. 


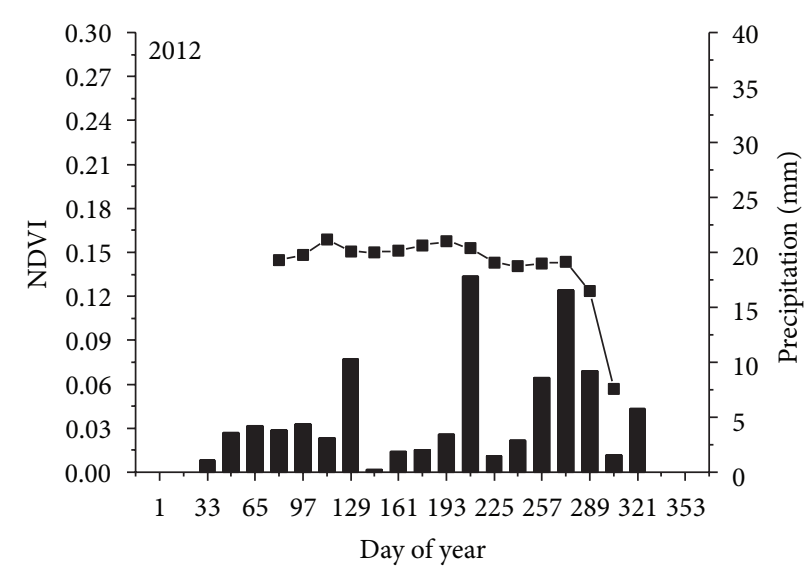

Figure 2: NDVI (only show the growing season) and precipitation in each 16-day period of the year from 2004 to 2012 for the shrubland within Gurbantunggut Desert.

was more correlated with the sum of precipitation in three to five 16-day periods than that in one or two periods in general. In terms of time lag, NDVI was more relative with the second and third preceding 16-day periods in general, but the statistical results were varied in different years (Table 2). With the time duration lengthening, the time lag for NDVI responding to precipitation was shortened.

\subsection{Cross-Season Relationship between NDVI and Precipi-} tation. There was also a considerable variation about the relationship between NDVI and precipitation in the different time periods within a year. The combination of time duration and lag influenced the relationship between NDVI and precipitation significantly. NDVI was significantly correlated with precipitation in all the time lags from May 9 to June 26 and in 3-5 time lags from August 13 to 29, while the relationship in the other periods was not so obvious (Table 3 ). In terms of time duration, the longer the duration was, the more the NDVI correlated with precipitation during the period that they correlated. In terms of time lags, NDVI was more strongly influenced by the current to fourth preceding 16-day periods during the period when NDVI correlated with precipitation on cross-season scale.

\subsection{Interannual Relationship between Precipitation and NDVI.} In the shrubland within Gurbantunggut Desert, total annual precipitation ranged from $102 \mathrm{~mm}$ to $185.9 \mathrm{~mm}$ and mean annual NDVI values ranged from 0.1559 to 0.1901 . The correlation coefficient between total annual precipitation and mean annual NDVI was 0.75 (greater than $P_{\alpha=0.05}=$ 0.67), which meant that annual mean NDVI was significantly correlated with total annual precipitation (Figure 3).

The correlation coefficients between mean annual NDVI and the accumulative precipitation for each 16-day period showed that the correlation coefficients increased steadily, became greater than $P_{\alpha=0.05}=0.67$ on the DOY 177, and kept steady until the end of the year (Figure 4 ).

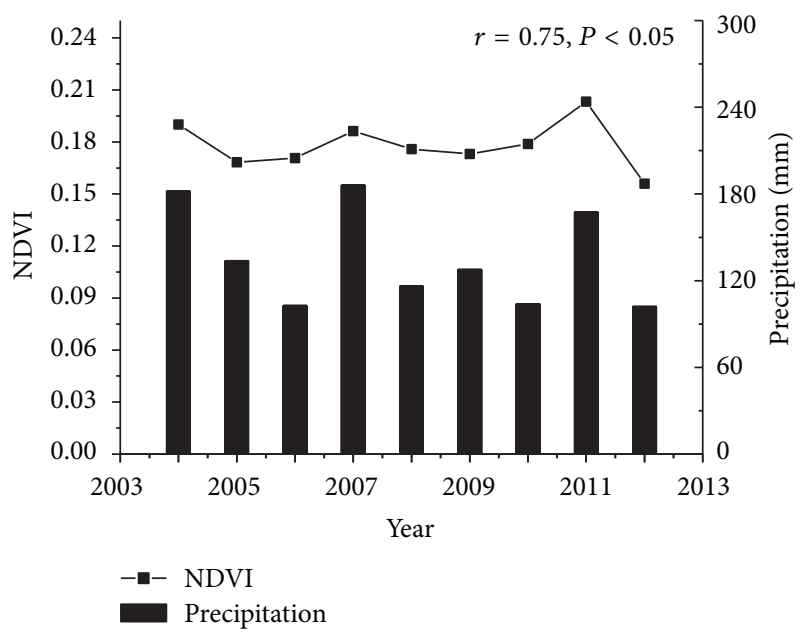

FIGURE 3: Total annual precipitation and mean NDVI during the growing season for the shrubland within Gurbantunggut Desert.

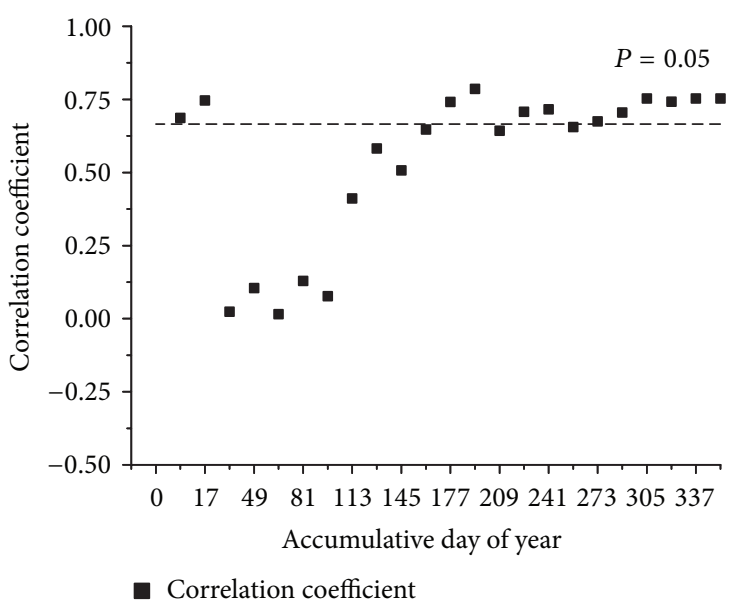

FIGURE 4: Correlation coefficients between mean annual NDVI and accumulative precipitation for each 16-day period in a year for the shrubland within Gurbantunggut Desert. 
TABLE 2: Within-season correlation coefficients between precipitation and NDVI of the shrubland within Gurbantunggut Desert. The numbers in the first column indicated the time interval for which precipitation is accumulated ( 0 indicated the current 16 -day period, 1 indicated the first previous period, $0-1$ indicated from current period to first previous period, etc.).

\begin{tabular}{|c|c|c|c|c|c|c|c|c|c|}
\hline Periods & 2004 & 2005 & 2006 & 2007 & 2008 & 2009 & 2010 & 2011 & 2012 \\
\hline 0 & 0.08 & -0.36 & 0.18 & 0.00 & -0.14 & 0.01 & 0.35 & 0.10 & -0.20 \\
\hline 1 & 0.22 & -0.34 & 0.37 & 0.10 & -0.02 & 0.34 & 0.27 & 0.21 & 0.13 \\
\hline 2 & 0.28 & -0.07 & 0.22 & 0.36 & 0.19 & 0.35 & 0.35 & 0.31 & -0.17 \\
\hline 3 & 0.47 & 0.33 & 0.24 & $0.79^{* *}$ & 0.34 & $0.53^{*}$ & 0.23 & 0.37 & $-0.57^{*}$ \\
\hline 4 & 0.24 & -0.04 & 0.38 & 0.40 & 0.27 & 0.46 & 0.14 & 0.47 & $-0.54^{*}$ \\
\hline 5 & -0.08 & -0.16 & 0.36 & -0.17 & $0.60^{*}$ & 0.51 & -0.12 & 0.21 & 0.07 \\
\hline $0-1$ & 0.22 & -0.52 & 0.38 & 0.06 & -0.12 & 0.24 & 0.45 & 0.22 & -0.05 \\
\hline $1-2$ & 0.36 & -0.31 & 0.41 & 0.30 & 0.13 & 0.49 & 0.47 & 0.36 & -0.03 \\
\hline $2-3$ & $0.56^{*}$ & 0.20 & 0.33 & $0.77^{* *}$ & 0.42 & $0.65^{* *}$ & 0.46 & 0.49 & $-0.56^{*}$ \\
\hline $3-4$ & $0.53^{*}$ & 0.23 & 0.45 & $0.82^{* *}$ & 0.51 & $0.76^{* *}$ & 0.29 & $0.62^{*}$ & $-0.77^{*}$ \\
\hline 4-5 & 0.12 & -0.16 & $0.52^{*}$ & 0.16 & $0.70^{* *}$ & $0.69^{* *}$ & 0.01 & 0.51 & -0.33 \\
\hline 5-6 & -0.14 & -0.33 & 0.25 & -0.34 & $0.59^{*}$ & $0.53^{*}$ & -0.28 & 0.25 & 0.15 \\
\hline $0-2$ & 0.36 & -0.50 & 0.49 & 0.24 & 0.01 & 0.35 & $0.64^{*}$ & 0.38 & -0.16 \\
\hline $1-3$ & $0.64^{*}$ & -0.06 & $0.55^{*}$ & $0.69^{* *}$ & 0.33 & $0.64^{*}$ & $0.59^{*}$ & $0.56^{*}$ & -0.46 \\
\hline $2-4$ & $0.66^{* *}$ & 0.15 & $0.57^{*}$ & $0.92^{* *}$ & $0.55^{*}$ & $0.75^{* *}$ & $0.53^{*}$ & $0.77^{* *}$ & $-0.81^{*}$ \\
\hline $3-5$ & 0.42 & 0.10 & $0.67^{* *}$ & $0.64^{*}$ & $0.80^{* *}$ & $0.78^{* *}$ & 0.18 & $0.75^{* *}$ & $-0.66^{*}$ \\
\hline $4-6$ & 0.04 & -0.33 & 0.49 & -0.06 & $0.66^{* *}$ & $0.62^{*}$ & -0.15 & $0.59^{*}$ & -0.20 \\
\hline $5-7$ & -0.20 & -0.23 & 0.28 & -0.32 & $0.57^{*}$ & 0.51 & -0.43 & 0.35 & 0.26 \\
\hline $0-3$ & $0.66^{* *}$ & -0.25 & $0.62^{*}$ & $0.58^{*}$ & 0.20 & 0.50 & $0.67^{* *}$ & 0.48 & $-0.52^{*}$ \\
\hline $1-4$ & $0.80^{* *}$ & -0.07 & $0.76^{* *}$ & $0.83^{* *}$ & 0.45 & $0.74^{* *}$ & $0.59^{*}$ & $0.70^{* *}$ & $-0.73^{*}$ \\
\hline $2-5$ & $0.61^{*}$ & 0.04 & $0.76^{* *}$ & $0.78^{* *}$ & $0.78^{* *}$ & $0.79^{* *}$ & 0.38 & $0.75^{* *}$ & $-0.73^{*}$ \\
\hline $3-6$ & 0.35 & -0.08 & $0.62^{*}$ & 0.42 & $0.74^{* *}$ & $0.73^{* *}$ & 0.02 & $0.69^{* *}$ & $-0.54^{*}$ \\
\hline $4-7$ & -0.05 & -0.22 & 0.49 & -0.08 & $0.62^{*}$ & $0.59^{*}$ & -0.29 & $0.57^{*}$ & -0.07 \\
\hline $5-8$ & -0.06 & -0.16 & 0.29 & -0.18 & $0.59^{*}$ & $0.54^{*}$ & -0.26 & 0.38 & 0.33 \\
\hline $0-4$ & $0.73^{* *}$ & -0.26 & $0.77^{* *}$ & $0.74^{* *}$ & 0.35 & $0.64^{*}$ & $0.69^{* *}$ & $0.62^{*}$ & $-0.70^{*}$ \\
\hline $1-5$ & $0.68^{* *}$ & -0.16 & $0.88^{* *}$ & $0.76^{* *}$ & $0.73^{* *}$ & $0.82^{* *}$ & 0.47 & $0.71^{* *}$ & $-0.59^{*}$ \\
\hline $2-6$ & 0.48 & -0.11 & $0.67^{* *}$ & $0.64^{*}$ & $0.81^{* *}$ & $0.79^{* *}$ & 0.24 & $0.71^{* *}$ & $-0.56^{*}$ \\
\hline $3-7$ & 0.23 & -0.02 & $0.58^{*}$ & 0.36 & $0.73^{* *}$ & $0.70^{* *}$ & -0.10 & $0.67^{* *}$ & -0.39 \\
\hline $4-8$ & 0.08 & -0.17 & 0.45 & 0.01 & $0.66^{* *}$ & $0.60^{*}$ & -0.15 & $0.57^{*}$ & 0.03 \\
\hline 5-9 & -0.04 & -0.13 & 0.11 & -0.23 & $0.67^{* *}$ & 0.40 & -0.17 & 0.15 & 0.35 \\
\hline
\end{tabular}

${ }^{*} P<0.05$ and ${ }^{* *} P<0.01$.

\section{Discussion}

The shrubland within Gurbantunggut Desert is a kind of ecosystem with a long growing season (from late March to early November) and the ecological process is variable within and cross the season/year. For understanding how the shrub vegetation within Gurbantunggut Desert responded to precipitation variability, correlation analyses between NDVI acquired from MODIS 16-day composite product at $250 \mathrm{~m}$ spatial resolution (MOD13Q1) and precipitation observed in automatic weather station near the study area were carried out within growing season, within cross growing season, and on interannual scale. The analytical results showed that NDVI was significantly correlated with the combination of time durations and time lags of precipitation, but not significantly correlated with the precipitation in the current period, which indicated that the shrub vegetation responded to the variability of the precipitation chronically and accumulatively, but not immediately or independently.
4.1. The Variability of the Shrub Vegetation and Its Relationship with Precipitation within and Cross Growing Season. The relationship between shrub vegetation and precipitation revealed a significant positive correlation during the study period, but the related patterns were varied in different years because of yearly precipitation amount and precipitation distribution within a year. The relationship between the yearly precipitation amount and the NDVI variational patterns was analyzed, and the result indicated that the bimodal pattern appeared in wet year (yearly precipitation amount higher than $153 \mathrm{~mm}$ ), the unimodal pattern appeared in normal year (yearly precipitation amount ranged from $111 \mathrm{~mm}$ to $153 \mathrm{~mm}$, except in the year of 2006), and the no-peak pattern appeared in dry year (yearly precipitation amount lower than $111 \mathrm{~mm}$, except in the year of 2005). The mean annual NDVI values among the bimodal, unimodal, and no-peak patterns were compared, and the result revealed that the relationship among the three patterns was $\mathrm{NDVI}_{\text {bimodal }}>\mathrm{NDVI}_{\text {unimodal }}>\mathrm{NDVI}_{\text {no-peak }}$ 
TABLE 3: Cross-season correlation coefficients between NDVI and precipitation in different combinations of time periods for the shrubland within Gurbantunggut Desert. The numbers in the first row indicated the periods for which precipitation was accumulated (1 indicated the current 16-day period, 2 indicated the sum of the current period and the first previous period, 3 indicated the sum of the current period, the first previous period, and the second previous period, etc.). The numbers in the first column indicated the time lags for the precipitation $(0$ indicated the current 16-day period, 1 indicated the first previous period, etc.).

\begin{tabular}{|c|c|c|c|c|c|c|}
\hline Lag & Day of year & 1 & 2 & 3 & 4 & 5 \\
\hline \multirow{15}{*}{0} & 81 (23/March) & 0.61 & 0.29 & -0.02 & 0.09 & 0.14 \\
\hline & 97 (7/April) & -0.07 & -0.30 & -0.54 & -0.40 & -0.35 \\
\hline & 113 (23/April) & 0.10 & -0.07 & 0.22 & 0.22 & 0.11 \\
\hline & 129 (9/May) & 0.36 & $0.73^{*}$ & $0.76^{*}$ & $0.81^{* *}$ & 0.64 \\
\hline & 145 (25/May) & 0.28 & 0.15 & $0.73^{*}$ & $0.83^{* *}$ & 0.39 \\
\hline & 161 (10/June) & 0.07 & $0.79^{*}$ & 0.66 & 0.29 & 0.45 \\
\hline & 177 (26/June) & $0.69^{*}$ & 0.41 & -0.09 & 0.05 & 0.03 \\
\hline & 193 (12/July) & -0.10 & -0.41 & -0.24 & -0.27 & -0.35 \\
\hline & 209 (28/July) & -0.27 & -0.15 & -0.10 & -0.16 & -0.07 \\
\hline & 225 (13/August) & 0.20 & 0.49 & 0.64 & 0.28 & 0.42 \\
\hline & 241 (29/August) & 0.37 & 0.52 & 0.20 & 0.36 & 0.42 \\
\hline & 257 (14/September) & 0.04 & -0.08 & 0.19 & 0.53 & 0.46 \\
\hline & 273 (30/September) & 0.05 & 0.21 & 0.54 & 0.53 & 0.52 \\
\hline & 289 (16/October) & 0.44 & 0.61 & 0.49 & 0.50 & 0.50 \\
\hline & 305 (1/November) & 0.33 & 0.07 & 0.14 & 0.15 & \\
\hline \multirow{15}{*}{1} & 81 (23/March) & 0.26 & $0.74^{*}$ & 0.37 & 0.09 & 0.18 \\
\hline & 97 (7/April) & -0.01 & -0.10 & -0.36 & -0.58 & -0.43 \\
\hline & 113 (23/April) & 0.36 & 0.28 & 0.17 & 0.33 & 0.33 \\
\hline & 129 (9/May) & $0.73^{*}$ & $0.73^{*}$ & $0.89^{* *}$ & $0.88^{* *}$ & $0.89^{* *}$ \\
\hline & 145 (25/May) & 0.62 & $0.74^{*}$ & $0.73^{*}$ & $0.89^{* *}$ & $0.83^{* *}$ \\
\hline & 161 (10/June) & 0.27 & 0.22 & $0.79^{*}$ & $0.73^{*}$ & 0.34 \\
\hline & 177 (26/June) & 0.17 & $0.74^{*}$ & 0.49 & -0.03 & 0.11 \\
\hline & 193 (12/July) & 0.66 & 0.43 & -0.05 & 0.15 & 0.11 \\
\hline & 209 (28/July) & -0.01 & -0.20 & -0.11 & -0.07 & -0.13 \\
\hline & 225 (13/August) & 0.11 & 0.18 & 0.25 & 0.26 & 0.21 \\
\hline & 241 (29/August) & 0.00 & 0.27 & 0.60 & 0.21 & 0.32 \\
\hline & 257 (14/September) & 0.54 & 0.35 & 0.18 & 0.38 & 0.61 \\
\hline & 273 (30/September) & -0.20 & -0.10 & 0.07 & 0.47 & 0.47 \\
\hline & 289 (16/October) & -0.26 & 0.04 & 0.30 & 0.20 & 0.22 \\
\hline & 305 (1/November) & 0.30 & 0.42 & 0.23 & 0.28 & 0.29 \\
\hline \multirow{15}{*}{2} & 81 (23/March) & 0.43 & 0.46 & $0.74^{*}$ & 0.53 & 0.23 \\
\hline & 97 (7/April) & 0.60 & 0.57 & 0.29 & -0.05 & -0.29 \\
\hline & 113 (23/April) & -0.22 & 0.30 & 0.24 & 0.10 & 0.29 \\
\hline & 129 (9/May) & 0.37 & 0.59 & $0.75^{*}$ & $0.80^{* *}$ & $0.81^{* *}$ \\
\hline & 145 (25/May) & $0.71^{*}$ & $0.90^{* *}$ & $0.88^{* *}$ & $0.85^{* *}$ & $0.95^{* *}$ \\
\hline & 161 (10/June) & 0.48 & 0.61 & 0.66 & $0.88^{* *}$ & $0.71^{*}$ \\
\hline & 177 (26/June) & -0.17 & 0.04 & 0.60 & 0.43 & -0.07 \\
\hline & 193 (12/July) & 0.13 & $0.69^{*}$ & 0.50 & 0.00 & 0.18 \\
\hline & 209 (28/July) & 0.47 & 0.36 & 0.08 & 0.17 & 0.21 \\
\hline & 225 (13/August) & 0.57 & 0.44 & 0.50 & 0.54 & 0.52 \\
\hline & 241 (29/August) & 0.48 & 0.49 & 0.56 & 0.57 & 0.51 \\
\hline & 257 (14/September) & 0.11 & 0.55 & 0.53 & 0.28 & 0.40 \\
\hline & 273 (30/September) & 0.65 & 0.21 & 0.20 & 0.29 & 0.59 \\
\hline & 289 (16/October) & -0.03 & -0.25 & 0.02 & 0.31 & 0.20 \\
\hline & 305 (1/November) & $-0.71^{*}$ & -0.36 & -0.10 & -0.21 & -0.17 \\
\hline
\end{tabular}


TABle 3: Continued.

\begin{tabular}{|c|c|c|c|c|c|c|}
\hline Lag & Day of year & 1 & 2 & 3 & 4 & 5 \\
\hline \multirow{15}{*}{3} & 81 (23/March) & 0.05 & 0.38 & 0.47 & $0.73^{*}$ & 0.56 \\
\hline & 97 (7/April) & 0.02 & 0.52 & 0.42 & 0.29 & -0.05 \\
\hline & 113 (23/April) & $0.90^{* *}$ & $0.69^{*}$ & $0.75^{*}$ & 0.60 & 0.44 \\
\hline & 129 (9/May) & -0.10 & 0.40 & 0.65 & $0.77^{*}$ & $0.83^{* *}$ \\
\hline & 145 (25/May) & 0.04 & 0.36 & $0.67^{*}$ & 0.63 & 0.62 \\
\hline & 161 (10/June) & $0.77^{*}$ & $0.83^{* *}$ & $0.82^{* *}$ & $0.84^{* *}$ & $0.96^{* *}$ \\
\hline & 177 (26/June) & 0.20 & 0.08 & 0.23 & 0.60 & 0.39 \\
\hline & 193 (12/July) & -0.26 & -0.04 & 0.53 & 0.41 & -0.06 \\
\hline & 209 (28/July) & 0.38 & 0.65 & 0.54 & 0.21 & 0.28 \\
\hline & 225 (13/August) & 0.12 & 0.60 & 0.58 & 0.59 & 0.65 \\
\hline & 241 (29/August) & 0.47 & 0.64 & 0.66 & $0.69^{*}$ & $0.69^{*}$ \\
\hline & 257 (14/September) & 0.21 & 0.25 & 0.36 & 0.32 & 0.29 \\
\hline & 273 (30/September) & -0.02 & 0.47 & 0.22 & 0.19 & 0.26 \\
\hline & 289 (16/October) & 0.28 & 0.14 & -0.10 & 0.12 & 0.34 \\
\hline & 305 (1/November) & -0.07 & -0.65 & -0.35 & -0.14 & -0.26 \\
\hline \multirow{15}{*}{4} & 81 (23/March) & 0.10 & 0.06 & 0.38 & 0.47 & $0.73^{*}$ \\
\hline & 97 (7/April) & -0.34 & -0.11 & 0.42 & 0.34 & 0.24 \\
\hline & 113 (23/April) & -0.15 & $0.68^{*}$ & 0.44 & $0.69^{*}$ & 0.59 \\
\hline & 129 (9/May) & 0.35 & 0.26 & 0.50 & $0.72^{*}$ & $0.82^{* *}$ \\
\hline & 145 (25/May) & 0.06 & 0.09 & 0.45 & $0.75^{*}$ & $0.69^{*}$ \\
\hline & 161 (10/June) & 0.05 & 0.40 & 0.63 & 0.59 & 0.62 \\
\hline & 177 (26/June) & 0.60 & 0.52 & 0.38 & 0.46 & 0.68 \\
\hline & 193 (12/July) & 0.29 & 0.11 & 0.22 & 0.58 & 0.41 \\
\hline & 209 (28/July) & -0.32 & 0.13 & 0.47 & 0.43 & 0.12 \\
\hline & 225 (13/August) & 0.27 & 0.26 & $0.73^{*}$ & 0.65 & 0.65 \\
\hline & 241 (29/August) & -0.07 & 0.37 & $0.68^{*}$ & $0.63^{*}$ & $0.70^{*}$ \\
\hline & 257 (14/September) & 0.49 & 0.46 & 0.51 & 0.57 & 0.52 \\
\hline & 273 (30/September) & 0.06 & 0.05 & 0.18 & 0.10 & 0.12 \\
\hline & 289 (16/October) & 0.39 & $0.70^{*}$ & 0.60 & 0.20 & 0.31 \\
\hline & 305 (1/November) & 0.08 & -0.01 & -0.58 & -0.31 & -0.09 \\
\hline \multirow{15}{*}{5} & 81 (23/March) & 0.06 & 0.08 & 0.06 & 0.38 & 0.47 \\
\hline & 97 (7/April) & -0.36 & -0.36 & -0.12 & 0.41 & 0.33 \\
\hline & 113 (23/April) & -0.35 & -0.25 & 0.58 & 0.35 & 0.65 \\
\hline & 129 (9/May) & -0.29 & 0.14 & 0.05 & 0.38 & $0.67^{*}$ \\
\hline & 145 (25/May) & 0.07 & 0.11 & 0.11 & 0.42 & $0.69^{*}$ \\
\hline & 161 (10/June) & 0.04 & 0.09 & 0.49 & $0.70^{*}$ & 0.65 \\
\hline & 177 (26/June) & -0.26 & 0.12 & 0.22 & 0.13 & 0.20 \\
\hline & 193 (12/July) & 0.42 & 0.48 & 0.30 & 0.37 & 0.61 \\
\hline & 209 (28/July) & 0.30 & 0.08 & 0.41 & 0.53 & 0.43 \\
\hline & 225 (13/August) & -0.11 & 0.17 & 0.19 & $0.69^{*}$ & 0.60 \\
\hline & 241 (29/August) & 0.35 & 0.13 & 0.54 & $0.77^{*}$ & $0.72^{*}$ \\
\hline & 257 (14/September) & 0.00 & 0.44 & 0.53 & 0.52 & 0.61 \\
\hline & 273 (30/September) & 0.32 & 0.25 & 0.25 & 0.33 & 0.26 \\
\hline & 289 (16/October) & 0.22 & 0.36 & 0.41 & 0.34 & 0.28 \\
\hline & 305 (1/November) & 0.37 & 0.51 & 0.40 & -0.32 & -0.09 \\
\hline
\end{tabular}

${ }^{*} P<0.05$ and ${ }^{* *} P<0.01$.

$\left(\mathrm{NDVI}_{\text {bimodal }}, \mathrm{NDVI}_{\text {unimodal }}\right.$ and $\mathrm{NDVI}_{\text {no-peak }}$ indicated the mean annual NDVI value for the bimodal, unimodal, and nopeak patterns, resp.). In the shrubland within Gurbantunggut Desert, Haloxylon ammodendron and Haloxylon persicum were the dominant species, which were dual-rooted droughtenduring perennial shrubs, accompanied with some grass and ephemerals under the canopy and intercanopy [39-43]. The variability of NDVI reflected the growth condition of 
Haloxylon ammodendron and Haloxylon persicum to some extent. In the early growing season, the vegetation growth and the NDVI value increased steadily and peaked in May of the year if there was enough water in the soil for plant use. The Haloxylon ammodendron and Haloxylon persicum are characteristic of falling off assimilation shoots and summer dormancy to avoid the harm from high temperature in the months of June and July $[44,45]$; thus the NDVI value in the middle growing season decreased. The vegetation physiological function revived gradually when the high temperature was falling in August, and enough water would be stored in the soil if there was a large amount of precipitation in July and August; then the vegetation grew quickly and the NDVI value reached another peak in August, forming bimodal pattern, like in the years of 2004, 2007, and 2011. If there was no large precipitation in the months of July or August, the vegetation growth was limited by available soil water, and another peak of NDVI value could not come into being, thus forming unimodal pattern, like in the years of 2006, 2008, and 2009. In the dry year, the growth of vegetation was limited by water, and the soil water was just used to keep the vegetation alive; therefore no peak of the NDVI value could appear, forming no-peak pattern, like in the years of 2005, 2010, and 2012.

The correlation analysis between NDVI and precipitation could be used to evaluate the relationship between the vegetation and precipitation. Within-season analysis showed that the relationship between NDVI and precipitation in any 16day period was not significant at any time lag, but significant correlation between NDVI and precipitation integrated in the previous two or three 16-day periods could be shown, which indicated that the shrub vegetation responded to the variability of precipitation chronically and accumulatively, but not immediately or independently. In the shrubland within Gurbantunggut Desert, Haloxylon ammodendron and Haloxylon persicum were the dominant species, which were the dual-rooted perennial wood shrubs and most fine roots distributed to a depth of $40-100 \mathrm{~cm}$ underground. It would take precipitation a long time to transform into effective soil water which plant roots could absorb because of high evaporation potential [39] and low precipitation intensity [46] in this region.

Cross-season analysis showed that in the early growing season (approximately from May 9 to June 26) NDVI was significantly correlated with precipitation occurring in the one to three periods before the current period and integrated in the previous one to four periods. And in another period when the second peak appeared in the bimodal pattern NDVI was significantly correlated with precipitation integrated in the previous three or four periods, but no significant correlation between NDVI and precipitation could be shown in the other periods of the growing season. As the dominant species in Gurbantunggut Desert, Haloxylon ammodendron and Haloxylon persicum were highly capable of adapting to the environment changes and were extremely competitive, especially for water $[42,45,47]$. It is in the period of May to June when Haloxylon ammodendron and Haloxylon persicum expanded their nourishment branch. If there was enough water stored in the soil, then the precipitation in this period could be used for plant growth, so NDVI and precipitation in this period were significantly correlative. In the month of August, the air temperature declined to such an extent that Haloxylon ammodendron and Haloxylon persicum could grow again, and the water accumulated in the soil could be used for plant use; therefore the vegetation growth condition in this period was significantly correlated with precipitation integrated in the previous three or four periods. In the other periods of growing season, the vegetation growth condition might be controlled by other factors, such as air temperature and physiological characteristics of plant; therefore the relationship between NDVI and precipitation in these periods was not so significant.

4.2. Interannual Relationship between the Shrubland Vegetation and Precipitation. The correlation analysis between mean annual NDVI during the growing season and total annual precipitation showed that total annual precipitation remarkably influenced the shrub vegetation within Gurbantunggut Desert. The correlation analysis between mean annual NDVI and within-year accumulative precipitation in each 16-day period showed that the accumulative precipitation before the DOY 177 (June 26) was not significantly correlated with mean annual NDVI but the relationship between them got more and more significant after June 26, which showed that most precipitation in the early days of the year was accumulated in the soil, forming inefficient soil water, and this part of precipitation could not influence the changes of the shrub vegetation directly; it just provided the soil with water to maintain the plant alive. But, from the middle days of the year, approximately June, the precipitation was accumulated enough for soil to hold, and the precipitation from June was used for plant to grow quickly.

\section{Conclusions}

This study focused on the relationship between shrub vegetation and precipitation within Gurbantunggut Desert during the growing season. Correlation analysis was employed to explore the relationship between NDVI, a representative for vegetation, and precipitation within growing season, within cross growing season, and on interannual scale. The results showed that NDVI could be classified into three changing patterns: bimodal, unimodal, and no-peak. The correlation analysis in growing season showed that NDVI was significantly correlated with the precipitation integrated by time durations and time lags. The correlation analysis on cross growing season scale showed that NDVI in the early growing season was significantly correlated with precipitation, but the relationship in the middle and late growing seasons was weak. The NDVI variational patterns depended on mean annual precipitation amount and the distribution of precipitation within a year. It is indicated in this study that the shrub vegetation variability within Gurbantunggut Desert was significantly correlated with precipitation chronically and accumulatively but not immediately or independently. With global climate change, precipitation regime has also been changed, and the vegetation in the desert ecosystem may be varied too. 


\section{Conflict of Interests}

The authors declare that there is no conflict of interests regarding the publication of this paper.

\section{Acknowledgments}

This study was supported by Key National 973 Project of China (no. 2013CB429905) and National Project of China (no. 2013BAC10B01 and no. KFJ-EW-STS-006-3). The authors thank the Fukang Station of Desert Ecology, Chinese Academy of Sciences, for sharing their weather data.

\section{References}

[1] F. Zhang, G. Zhou, Y. Wang, F. Yang, and C. Nilsson, "Evapotranspiration and crop coefficient for a temperate desert steppe ecosystem using eddy covariance in Inner Mongolia, China," Hydrological Processes, vol. 26, no. 3, pp. 379-386, 2012.

[2] L. Li, G. Luo, X. Chen et al., "Modelling evapotranspiration in a Central Asian desert ecosystem," Ecological Modelling, vol. 222, no. 20-22, pp. 3680-3691, 2011.

[3] X.-P. Wang, C. M. Brown-Mitic, E.-S. Kang, J.-G. Zhang, and X.-R. Li, "Evapotranspiration of Caragana korshinskii communities in a revegetated desert area: tengger Desert, China," Hydrological Processes, vol. 18, no. 17, pp. 3293-3303, 2004.

[4] S. Kimball, A. L. Angert, T. E. Huxman, and D. L. Venable, "Contemporary climate change in the Sonoran Desert favors cold-adapted species," Global Change Biology, vol. 16, no. 5, pp. 1555-1565, 2010.

[5] S. M. Munson, R. H. Webb, J. Belnap, J. A. Hubbard, D. E. Swann, and S. Rutman, "Forecasting climate change impacts to plant community composition in the Sonoran Desert region," Global Change Biology, vol. 18, no. 3, pp. 1083-1095, 2012.

[6] R. Salguero-Gómez, W. Siewert, B. B. Casper, and K. Tielbörger, "A demographic approach to study effects of climate change in desert plants," Philosophical Transactions of the Royal Society B: Biological Sciences, vol. 367, no. 1606, pp. 3100-3114, 2012.

[7] Q. Wang, R. J. Abbott, Q.-S. Yu, K. Lin, and J.-Q. Liu, "Pleistocene climate change and the origin of two desert plant species, Pugionium cornutum and Pugionium dolabratum (Brassicaceae), in northwest China," New Phytologist, vol. 199, no. 1, pp. 277-287, 2013.

[8] J.-L. Liu, F.-R. Li, C.-A. Liu, and Q.-J. Liu, "Influences of shrub vegetation on distribution and diversity of a ground beetle community in a Gobi desert ecosystem," Biodiversity and Conservation, vol. 21, no. 10, pp. 2601-2619, 2012.

[9] X. W. Chuai, X. J. Huang, W. J. Wang, and G. Bao, "NDVI, temperature and precipitation changes and their relationships with different vegetation types during 1998-2007 in Inner Mongolia, China," International Journal of Climatology, vol. 33, no. 7, pp. 1696-1706, 2013.

[10] S. X. Yao, C. C. Zhao, T. H. Zhang, and X. P. Liu, "Response of the soil water content of mobile dunes to precipitation patterns in Inner Mongolia, northern China," Journal of Arid Environments, vol. 97, pp. 92-98, 2013.

[11] K. J. Tobin and M. E. Bennett, "Temporal analysis of Soil and Water Assessment Tool (SWAT) performance based on remotely sensed precipitation products," Hydrological Processes, vol. 27, no. 4, pp. 505-514, 2013.
[12] M. C. Ramos and J. A. Martínez-Casasnovas, "Effects of precipitation patterns and temperature trends on soil water available for vineyards in a Mediterranean climate area," Agricultural Water Management, vol. 97, no. 10, pp. 1495-1505, 2010.

[13] J. E. Bell, R. Sherry, and Y. Q. Luo, "Changes in soil water dynamics due to variation in precipitation and temperature: an ecohydrological analysis in a tallgrass prairie," Water Resources Research, vol. 46, no. 3, Article ID W03523, 2010.

[14] C. L. Hanson, C. A. Moffet, J. R. Wight, and J. E. Mowbray, "Ekalaka, Montana small watershed data set: precipitation, runoff, air temperature, and soil water, 1968-1980," Water Resources Research, vol. 41, no. 12, Article ID W12435, 2005.

[15] J. F. Reynolds, P. R. Kemp, K. Ogle, and R. J. Fernández, "Modifying the 'pulse-reserve' paradigm for deserts of North America: precipitation pulses, soil water, and plant responses," Oecologia, vol. 141, no. 2, pp. 194-210, 2004.

[16] S. Chamaillé-Jammes and H. Fritz, "Precipitation-NDVI relationships in eastern and southern African savannas vary along a precipitation gradient," International Journal of Remote Sensing, vol. 30, no. 13, pp. 3409-3422, 2009.

[17] T. E. Huxman, M. D. Smith, P. A. Fay et al., "Convergence across biomes to a common rain-use efficiency," Nature, vol. 429, no. 6992, pp. 651-654, 2004.

[18] E. G. Jobbágy, O. E. Sala, and J. M. Paruelo, "Patterns and controls of primary production in the Patagonian steppe: a remote sensing approach," Ecology, vol. 83, no. 2, pp. 307-319, 2002.

[19] P. Camberlin, N. Martiny, N. Philippon, and Y. Richard, "Determinants of the interannual relationships between remote sensed photosynthetic activity and rainfall in tropical Africa," Remote Sensing of Environment, vol. 106, no. 2, pp. 199-216, 2007.

[20] T.-W. Kim, R. G. Najjar, and K. Lee, "Influence of precipitation events on phytoplankton biomass in coastal waters of the eastern United States," Global Biogeochemical Cycles, vol. 28, no. 1, pp. 1-13, 2014.

[21] F. H. Hao, X. Zhang, W. Ouyang, A. K. Skidmore, and A. G. Toxopeus, "Vegetation NDVI linked to temperature and precipitation in the upper catchments of Yellow river," Environmental Modeling and Assessment, vol. 17, no. 4, pp. 389-398, 2012.

[22] L. Gómez-Mendoza, L. Galicia, M. L. Cuevas-Fernández, V. Magaña, G. Gómez, and J. L. Palacio-Prieto, "Assessing onset and length of greening period in six vegetation types in Oaxaca, Mexico, using NDVI-precipitation relationships," International Journal of Biometeorology, vol. 52, no. 6, pp. 511-520, 2008.

[23] W. Thavorntam and N. Tantemsapya, "Vegetation greenness modeling in response to climate change for Northeast Thailand," Journal of Geographical Sciences, vol. 23, no. 6, pp. 10521068, 2013.

[24] F. Li, W. Z. Zhao, and H. Liu, "The response of aboveground net primary productivity of desert vegetation to rainfall pulse in the temperate desert region of northwest China," PLoS ONE, vol. 8, no. 9, Article ID e73003, 2013.

[25] T. Wang, X. Kou, Y. Xiong, P. Mou, J. Wu, and J. Ge, “Temporal and spatial patterns of NDVI and their relationship to precipitation in the Loess Plateau of China," International Journal of Remote Sensing, vol. 31, no. 7, pp. 1943-1958, 2010.

[26] M. J. Ding, Y. L. Zhang, L. S. Liu, W. Zhang, Z. F. Wang, and W. Q. Bai, "The relationship between NDVI and precipitation on the Tibetan Plateau," Journal of Geographical Sciences, vol. 17, no. 3, pp. 259-268, 2007.

[27] J. Wang, P. M. Rich, and K. P. Price, “Temporal responses of NDVI to precipitation and temperature in the central Great 
Plains, USA," International Journal of Remote Sensing, vol. 24, no. 11, pp. 2345-2364, 2003.

[28] T. R. Robertson, C. W. Bell, J. C. Zak, and D. T. Tissue, "Precipitation timing and magnitude differentially affect aboveground annual net primary productivity in three perennial species in a Chihuahuan Desert grassland," New Phytologist, vol. 181, no. 1, pp. 230-242, 2009.

[29] M. T. Schnur, H. Xie, and X. Wang, "Estimating root zone soil moisture at distant sites using MODIS NDVI and EVI in a semiarid region of southwestern USA," Ecological Informatics, vol. 5, no. 5, pp. 400-409, 2010.

[30] J. C. De Oliveira, J. C. N. Epiphanio, and C. D. Rennó, "Window regression: a spatial-temporal analysis to estimate pixels classified as low-quality in MODIS NDVI time series," Remote Sensing, vol. 6, no. 4, pp. 3123-3142, 2014.

[31] C. Munyati and G. Mboweni, "Variation in NDVI values with change in spatial resolution for semi-arid savanna vegetation: a case study in Northwestern South Africa," International Journal of Remote Sensing, vol. 34, no. 7, pp. 2253-2267, 2013.

[32] G. le Maire, C. Marsden, W. Verhoef et al., "Leaf area index estimation with MODIS reflectance time series and model inversion during full rotations of Eucalyptus plantations," Remote Sensing of Environment, vol. 115, no. 2, pp. 586-599, 2011.

[33] M. L. Clark, T. M. Aide, H. R. Grau, and G. Riner, "A scalable approach to mapping annual land cover at $250 \mathrm{~m}$ using MODIS time series data: a case study in the Dry Chaco ecoregion of South America," Remote Sensing of Environment, vol. 114, no. 11, pp. 2816-2832, 2010.

[34] S. M. Jin and S. A. Sader, "MODIS time-series imagery for forest disturbance detection and quantification of patch size effects," Remote Sensing of Environment, vol. 99, no. 4, pp. 462-470, 2005.

[35] J. Li, C. Zhao, H. Zhu, Y. Li, and F. Wang, "Effect of plant species on shrub fertile island at an oasis-desert ecotone in the South Junggar Basin, China," Journal of Arid Environments, vol. 71, no. 4, pp. 350-361, 2007.

[36] T. C. Huang, S. J. Chen, and M. Hou, “The NDVI time effect of Haloxylonammodendron forest in gurbantunnggut desert: based on phenological changes and the image of MODIS," Remote Sensing Technology and Application, vol. 27, no. 5, pp. 784-789, 2012.

[37] J. H. Sheng, H. Y. Liu, D. Z. Pan, X. J. Yang, and Z. X. Zhai, "Study on phonological phases of Haloxylon ammodendron (C. A. Mey.) Bunge," Journal of Agricultural Science and Techology, vol. 5, no. 3, pp. 60-63, 2003 (Chinese).

[38] Y. Richard and I. Poccard, "A statistical study of NDVI sensitivity to seasonal and interannual rainfall variations in Southern Africa," International Journal of Remote Sensing, vol. 19, no. 15, pp. 2907-2920, 1998.

[39] X. M. Cao, J. L. Wang, X. Chen, Z. Q. Gao, F. Yang, and J. K. Shi, "Multiscale remote-sensing retrieval in the evapotranspiration of Haloxylon ammodendron in the Gurbantunggut desert, China," Environmental Earth Sciences, vol. 69, no. 5, pp. 15491558, 2013.

[40] J. Li, C. Y. Zhao, Y. J. Song, Y. Sheng, and H. Zhu, "Spatial patterns of desert annuals in relation to shrub effects on soil moisture," Journal of Vegetation Science, vol. 21, no. 2, pp. 221232,2010

[41] Y. Y. Song, Y. Y. Li, and M. Y. Li, "The cycle characteristics of Haloxylon ammodendron pattern and topography at multiscales in Gurbantunggut Desert, China," Russian Journal of Ecology, vol. 44, no. 5, pp. 381-386, 2013.
[42] H. Xu and Y.Li, "Water-use strategy of three central Asian desert shrubs and their responses to rain pulse events," Plant and Soil, vol. 285, no. 1-2, pp. 5-17, 2006.

[43] T. Zou, Y. Li, H. Xu, and G.-Q. Xu, "Responses to precipitation treatment for Haloxylon ammodendron growing on contrasting textured soils," Ecological Research, vol. 25, no. 1, pp. 185-194, 2010.

[44] T. Yu, C. Ren, J. Zhang et al., "Effect of high desert surface layer temperature stress on Haloxylon ammodendron (C.A. Mey.) Bunge," Flora, vol. 207, no. 8, pp. 572-580, 2012.

[45] P. X. Su, G. D. Cheng, Q. D. Yan, and X. M. Liu, "Photosynthetic regulation of $\mathrm{C}_{4}$ desert plant Haloxylon ammodendron under drought stress," Plant Growth Regulation, vol. 51, no. 2, pp. 139$147,2007$.

[46] L. Xu, H. Zhou, C. Liang, L. Du, and H. Li, "Spatial and temporal variability of annual and seasonal precipitation over the desert region of China during 1951-2005," Hydrological Processes, vol. 24, no. 20, pp. 2947-2959, 2010.

[47] G.-Q. Xu, Y. Li, and H. Xu, "Seasonal variation in plant hydraulic traits of two co-occurring desert shrubs, Tamarix ramosissima and Haloxylon ammodendron, with different rooting patterns," Ecological Research, vol. 26, no. 6, pp. 1071-1080, 2011. 

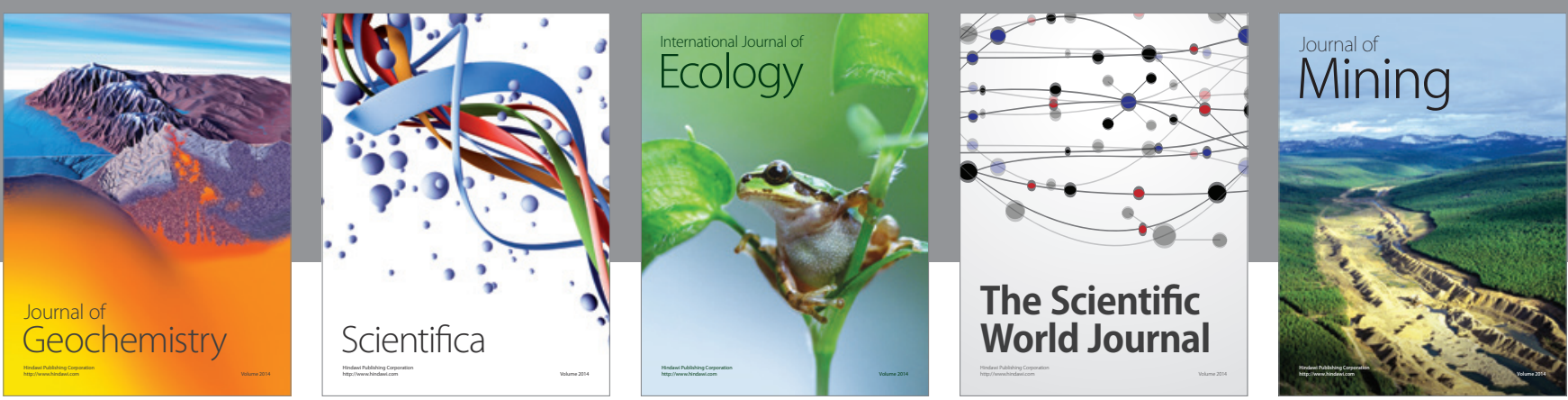

The Scientific World Journal
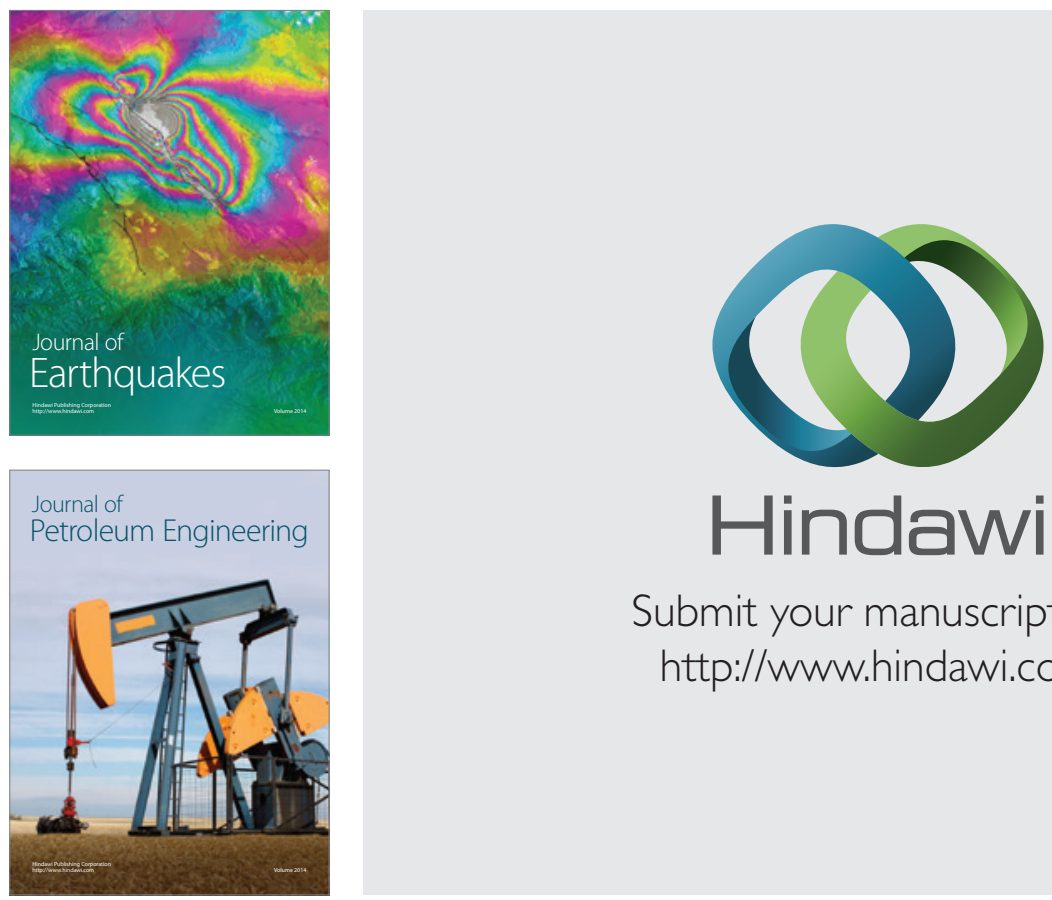

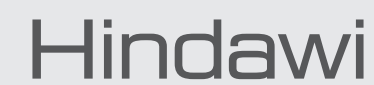

Submit your manuscripts at

http://www.hindawi.com
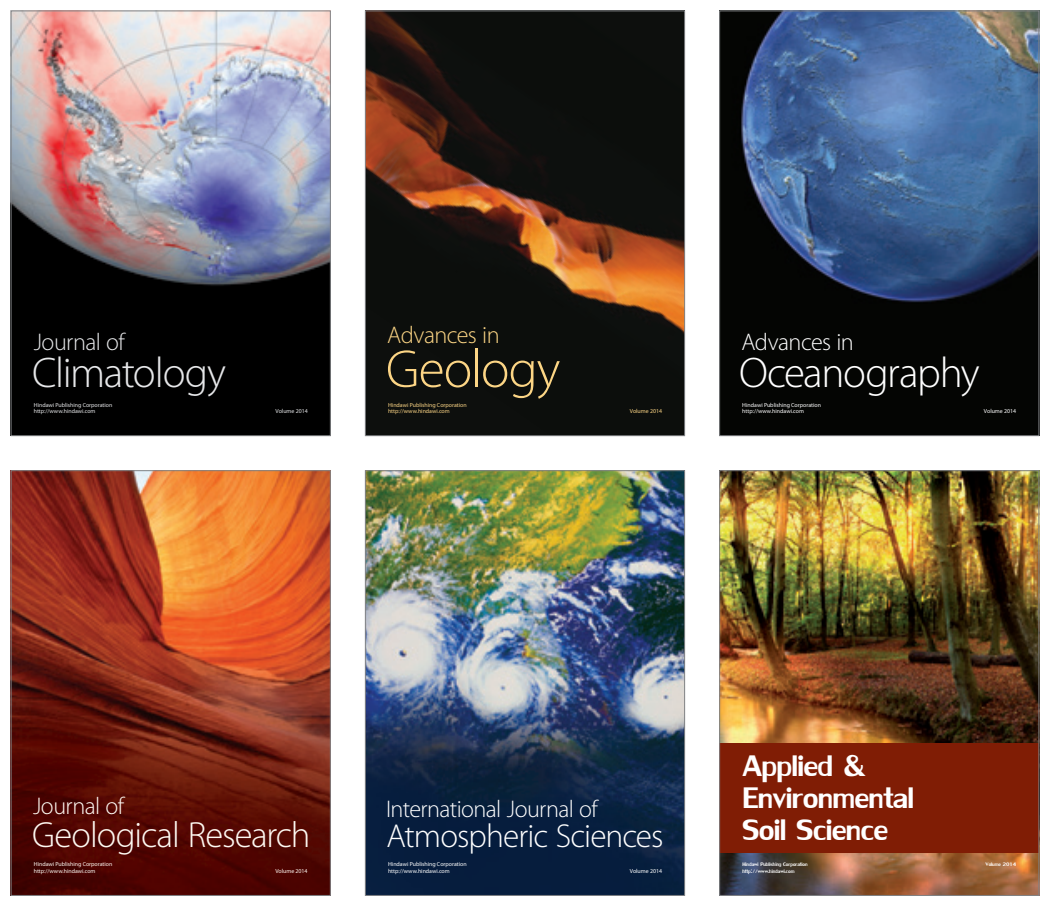
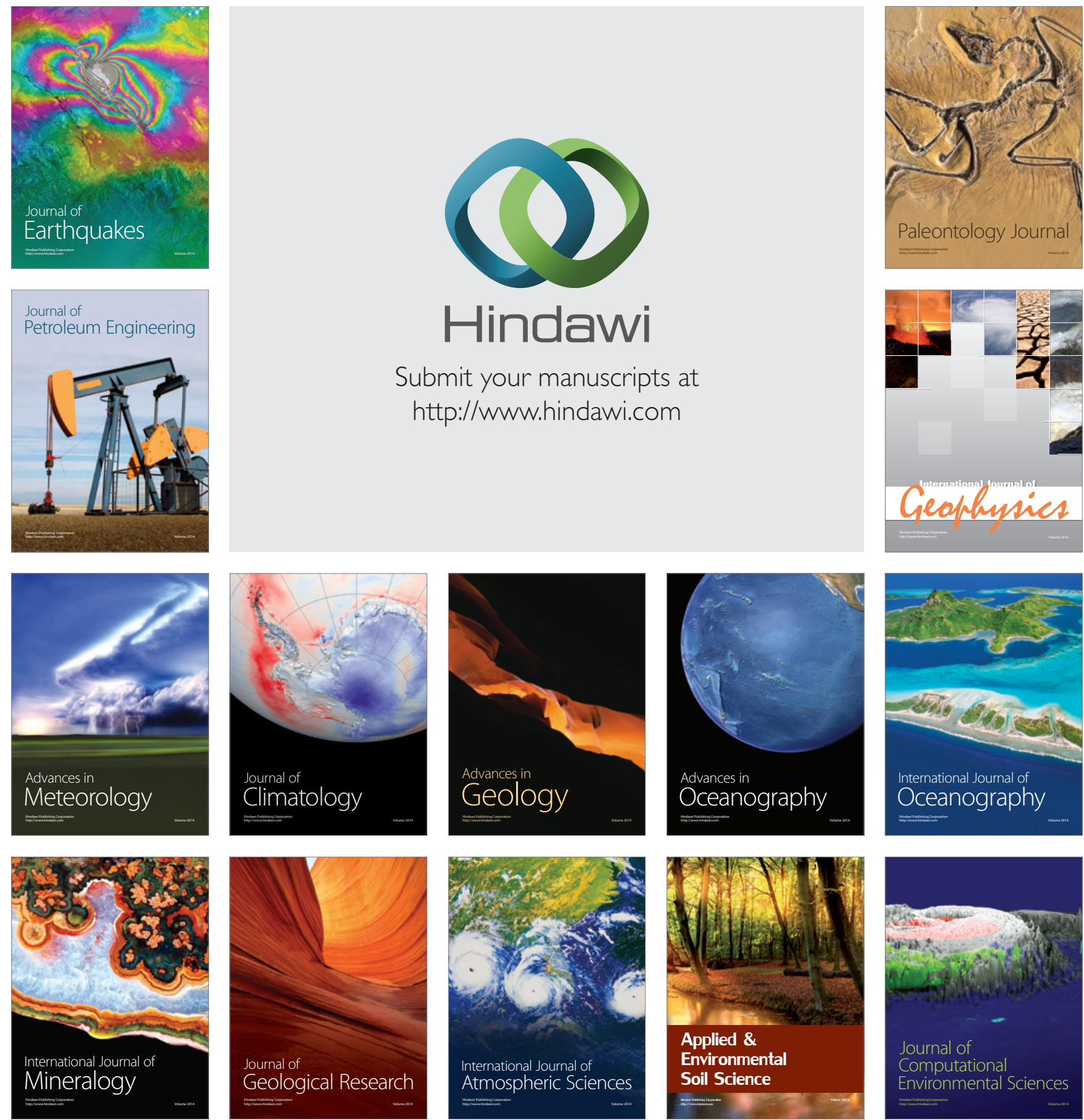